\title{
Safety of a dust mite extract in severe allergic asthma
}

\author{
Ruperto González-Pérez ${ }^{1 *}$, Paloma Poza-Guedes², Inmaculada Sánchez-Machín², Victor Matheu² \\ From EAACI International Severe Asthma Forum (ISAF 2012) \\ Gothenburg, Sweden. 11-13 October 2012
}

\section{Background}

The main goal of the current study was to evaluate the clinical tolerance of a modified dust mite subcutaneous extract in a small subset of severe extrinsic asthmatic subjects.

\section{Methods}

We selected 3 adult patients with a confirmed diagnosis of severe persistent allergic asthma (ATS criteria for severe asthma) for at least five years. Mean average topical steroid (inhaled) daily dose was above $1000 \mathrm{mcg}$ of fluticasone propionate or $1600 \mathrm{mcg}$ of budesonide. All patients included in the current trial were clinically relevant sensitized to dust mites (Dermatophagoides spp.) as shown by skin prick test and/or specific IgE. Inclusion criteria required no hospital or emergency admissions for the last 2 months with no changes in their daily medication in the last four weeks prior to the administration of immunotherapy. No pre-treatment with systemic steroids and/ or antihistaminics were used. Modified standardized specific dust mites immunotherapy extracts were subcutaneously administered according to a validated protocol to achieve a final dose of $100 \mathrm{DDP} / \mathrm{ml}$ in a two-week cluster schedule. None of the subjects in both groups have been previously treated with omalizumab. Clinical observation and lung function was strictly monitored in all subjects until the maintenance dose of immunotherapy was reached.

\section{Results}

The three patients could reach the proposed allergen dose according to the immunotherapy schedule in two weeks. No significant adverse reactions were recorded, with no changes in the lung function. Minor immediate local reactions at the injections site were only observed

${ }^{1}$ Hospital del Tórax-Ofra, Spain

Full list of author information is available at the end of the article at the maximal allergen dose in 2 patients showing a good response to oral antihistaminics in all cases. No late adverse reactions were present.

\section{Conclusion}

The standardized specific allergen immunotherapy dose was successfully reached in a small group of severe persistent allergic asthmatics. Further studies are needed to evaluate the role of specific immunotherapy in controlled severe allergic asthma.

\section{Author details}

${ }^{1}$ Hospital del Tórax-Ofra, Spain. ${ }^{2}$ Hospital del Tórax-Ofra, Allergy, Spain.

Published: 3 May 2013

\section{doi:10.1186/2045-7022-3-S1-P30}

Cite this article as: González-Pérez et al:: Safety of a dust mite extract in severe allergic asthma. Clinical and Translational Allergy 2013 3(Suppl 1): P30
Submit your next manuscript to BioMed Central and take full advantage of:

- Convenient online submission

- Thorough peer review

- No space constraints or color figure charges

- Immediate publication on acceptance

- Inclusion in PubMed, CAS, Scopus and Google Scholar

- Research which is freely available for redistribution

Submit your manuscript at www.biomedcentral.com/submit
() Biomed Central

\section{(Ciomed Central}

